\title{
Effect of Health Educational Program for Females Blinded Adolescents Students regarding Reproductive Health
}

\author{
Rasmia Abd-El Sattar Ali ${ }^{1}$, Ebtisam Mohamed Abd-El Aal ${ }^{2, *}$ \\ ${ }^{1}$ Lecturer of Community Health Nursing, Faculty of Nursing, Ain Shams University, Egypt \\ ${ }^{2}$ Assistant Professor of Community Health Nursing, Faculty of Nursing, Banha University Egypt \\ Email address: \\ S0124295493@hotmail.com (R. Abd-El S. A.), ebtisam_rohayem@yahoo.com (E. M. Abd-El A.)
}

\section{To cite this article:}

Rasmia Abd-El Sattar Ali, Ebtisam Mohamed Abd-El Aal. Effect of Health Educational Program for Females Blinded Adolescents Students Regarding Reproductive Health. American Journal of Nursing Science. Vol. 4, No. 1, 2015, pp. 1-8.

doi: $10.11648 /$ j.ajns.20150401.11

\begin{abstract}
Reproductive health is one of the most fundamental aspects of life and it received little attention in public policy discussions because of cultural and political sensitivities. The study aimed to evaluate the effectiveness of health educational program for females blinded adolescents students regarding reproductive health. Research design: A quasi-experimental study was used. Setting: The study was conducted in El-Nor and El-Aml institute affiliated to the Ministry of Health and Population. Sample Convenient sample of all students attended to El-Nor and El-Aml institutional setting, staying and not staying at institute, undergoing the following criteria: Aged 10-18 years and free from medical problems. Tools: Two tools were used I): An interviewing questionnaire which include three parts 1) socio-demographic characteristics. 2) Knowledge about reproductive system. 3): Health problems during last six months related to reproductive system. II): Observational checklist that included questions about reproductive health practices regarding nutrition, personal hygiene, exercise, follow-up for reproductive health problems, sleep, and reproductive health. Results: around half of students(57.7\%) not staying at El-Nor and El-Aml institution, and about two thirds (64.8\%) of them living in urban area. There is a statistically significant improvement between pre-test and post-test results regarding nutrition, personal hygiene, exercise, follow-up, sleep, and reproductive health. Conclusion: Females blinded adolescents students' knowledge and practices in El-Nor and El-Aml institution were improved health after implementation of the health education program about reproductive health. Recommendations Continuous health educational program by using suitable strategies should be provided to this target population.
\end{abstract}

Keywords: Adolescent, Reproductive Health, Blinded Female

\section{Introduction}

Adolescence is a critical period in girls' lives as they transition from childhood to the responsibilities of adulthood. With a better understanding of their bodies and of their own physical and psychological changes, young people can go through puberty more confidently. Comprehensive sexuality education helps empower young people to protect their health and well-being as they grow and take on family responsibilities ${ }^{[1]}$.

Blindness is devastating physical condition with deep emotional and economic implications. The blindness causes major changes in lifestyle, habits of blind female which may result in problems in physical, psychological and social adjustments ${ }^{[2]}$.It has a serious effect on the female adolescent students, family and community. As it considered the most traumatic sensory impairment where vision is one of the most important channels through which the adolescent is informed about environment and it is vital in coordinating experiences ${ }^{[3]}$.

According to $\mathrm{WHO}^{[4]}$, estimation the percentage of vision impairment were 148 million worldwide would be blind, and 110 million cases of low vision that would be at risk of becoming blind reported. Approximately $90 \%$ of the world visually impaired people live in the developing countries; this means that 9 out of 10 who are visually impaired live in the developing country as well.

Reproductive health is a state of complete physical, mental and social well-being in all matters related to the reproductive system, it means that all people should have a satisfying and safe sexual life. Disabled people should be 
allowed to reproduce while maintaining the freedom to decide when and how often to do so. This requires that sexual health be included in the entire health package to enhance the personal lives seeking early intervention (Population, Reproductive Rights and Reproductive Health $)^{[5]}$.

In Egypt, adolescents receive very limited SRH (Sexual Reproductive Health) education through the formal school system. Both national and subnational surveys have shown that young Egyptians lack basic information on SRH topics and often receive information from sources that may be misleading or inaccurate. Surveys also have shown that both young people and their parents would like more information on these topics to be taught at school ${ }^{[1]}$.

The community health nurse can advocate for blind female students, improving their needs by designing programs to promote their healthy life style or even jointing in teaching classes focusing on the targeted areas of nutrition, physical activity, stress management, family planning, injury prevention and health protection from hazards such as smoking, substance abuse and dangers of spread of sexually transmitted diseases ${ }^{[6]}$.

\subsection{Significance of the Study}

The prevalence of low vision in all ages in Egypt is 3.1\% that is nearly equal to 2.3 million of people. The prevalence of blindness is $1.1 \%$ that is nearly equal to 737.000 blind people. Without proper intervention, the number of blind in Egypt will increase to over one million by $2020^{[7,8]}$.

\subsection{Aim of the Study}

The study aimed to evaluate the effectiveness of health education program for females blinded adolescents students about reproductive health, through:

1. Identifying the knowledge and practices of females blinded adolescents students about reproductive health.

2. Determining health problems in the last six months of female blinded adolescents toward reproductive system.

3. Designing, implementing, and evaluating the effectiveness of the health educational program to improve their knowledge and practices to prevent health problems regarding reproductive health.

\subsection{Research Hypothesis}

The health educational program will improve the knowledge and practices of females blinded adolescents students in El-Nor and El-Aml Institute.

\section{Subjects and Methods}

\subsection{Research Design}

A quasi-experimental design was used to conduct this study.

\subsubsection{Setting}

The study was conducted in El- Nor and El- Aml Institute affiliated to the Ministry of Health and Population, in Cairo
City.

\subsubsection{Subjects}

Convenient sample of all students attended to El-Nor and El-Aml institutional setting, staying and not staying at institute, with the following criteria: Aged 10-18 years and free from medical health problems.

\subsubsection{Tools of Data Collection}

I): An interviewing questionnaire which include three parts 1) students' characteristics as age, residence, living place, mother education, mother occupation, needs helper. 2):Knowledge about reproductive system as meaning of reproductive health, parts of reproductive system, changes with menstruation, symptoms of reproductive problems, menstrual duration, function of reproductive system, reproductive hormones, glands controlled menstruation, diet should be increased during adolescence, exercise. 3): Health problems during last six months as vaginal itching, discharge with bad odor, lower abdominal pain.

\subsubsection{Scoring System}

The female students' knowledge was calculated for each item as follows: Complete and /or correct answer was scored (2), Incomplete correct answer was scored (1), while don't know or wrong answer was scored (0). The total score was calculated as: Satisfactory $>=60 \%$ of the total score and Unsatisfactory $<60 \%$ of the total score.

II) Students' practices tool through asking question about reproductive health regarding nutrition it included 11 items as taking breakfast, taking vegetables and fruits, drinking milk, decreasing fast foods, taking all food content especially iron, increasing hot fluid during menstruation, decreasing pottered foods, taking three meals daily and snacks, decreasing tea and coffee, decreasing taking cola. Personal hygiene includes 6 items as bathing one or more weekly, increasing bathing during menstruation, changing menstrual bad four times daily, using antiseptic solution for cleanliness, using cotton underwear, remove pubic and axillary hair. Exercise: practicing sports daily, decreasing sport during menstruation, perform hip exercise during menstruation.

\subsection{Scoring System}

The female students' practices were calculated for each item as follows: regular practices were scored (2), while sometimes practices were scored (1), and never practices were scored (0). The total score was calculated as: Satisfactory $\geq 60 \%$ of the total score and unsatisfactory $<60 \%$ of the total score

Validity: Content validity was done through five experts from Faculty Members of Community Health Nursing and staff members of El-Nor and El-Aml Institute.

Reliability: Reliability coefficients were calculated for questionnaire items. The coefficient alpha was 0.91 .

Ethical consideration: All relevant ethical aspects were considered for ensuring the confidentiality of the collected data through; gaining oral consent for participation in the study, explaining the purpose of the study, right to refuse to continue participation at any time without giving any reasons. 
Pilot study: was carried out on ten female students to assess the tool clarity, applicability, and time needed to fill each sheet. The pilot study was excluded from the main study sample.

\subsection{Field Work}

- Preparation of data collection was carried out from the beginning of April 2013 to the end of May 2013 and data collection from beginning of September 2013 to end of December 2013.

- An official letter was issued from the Dean of the Faculty of Nursing to the director of El-Nor and El-Aml institute including the aim of the study.

- Approval was taken from the director and oral consent from each student to conduct the study.

- Explanation of the purpose of the research was done to the head master and the staff working in the school as teachers and social worker to gain their cooperation.

- The researchers conducted the program twice/week (Saturdays and Thursdays), from 10.00 a.m. to 1.00 p.m.

- The students were interviewed individually by the researcher to fill out the sheet. After that all students were divided into 5 groups three in preparatory school and two groups for secondary students, each group includes 5-7 students to implement the program.

- The interview was done in the playground and library meeting continuous. Until the program completed

\subsection{Health Educational Program Construction}

The program was conducted at four phases:

1- Preparatory phase: A review of recent, current, national and international literature in various aspects of the problem. The tools questionnaire was designed to assess the reproductive health among blind adolescent students' (knowledge and practices) before and after implementing the program.

2- The assessment phase: The pre test questionnaire was designed and implemented to identify the reproductive health problems as self reported by the students, students' knowledge about reproductive health and their practices to prevent reproductive health problems.

3- The planning and implementing phase: The intervention program was designed, with general objective was to evaluate the effect of health education program for female blinded adolescent about reproductive health.

The program content included:

- Reproductive system (meaning, Parts of reproductive system, Changes with menstruation, Dangerous signs, Normal days of menstruation, Function of reproductive health, Time of ovulation, Glands for menstrual regulation, Normal periods between menstruation, Femenial hormones.

- Reproductive health practices to prevent reproductive health problems (nutrition, personal hygiene, exercise, follow-up, psychological, and sleep)

The program includes four sessions 2 for theory and 2 for practice.

Each session takes from 30-45 minutes for theory and practical.

At the end of the program implemented, a booklet of the program was given to each student translated to brill typing as a reference.

A post test was done to evaluate the effect of the health program on improving students' practices and their upgrading knowledge.

The teaching methods used were discussions, brainstorming, demonstration and re-demonstration. Brill booklets were distributed as teaching media.

\subsection{The Fourth: Evaluating Phase}

To evaluate the effect of the health educational program of blind adolescents' students' knowledge and practices about reproductive health through using post test that similar to the pre test was applied.

\subsection{Statistical Design}

The calculated data was analyzed and tabulated using "chi square" for number and percentage distribution, and independent " $\mathrm{t}$ " test was used for mean and standard division, and correlation coefficient " $r$ " was used; by using SPSS, version 16 to determine if there are statistically significance relations.

\section{Results}

Table (1): Shows that the mean age of students $15.07 \pm 1.17$, 57.7 not staying at El-Nor and El-Aml Institute, about $64.8 \%$ living in urban areas, $71.8 \%$ of mothers had secondary education 57.7 of mothers housewives, and about $63.4 \%$ needs helper.

Table (1). Frequency distribution of study sample regarding students' demographic characteristics $(n=71)$.

\begin{tabular}{lll}
\hline Students' demographic & No & \% \\
\hline Age/ years & & \\
$\leq 15$ & 47 & 66.2 \\
$>15$ & 24 & 33.8 \\
Mean \pm SD & 15.07 & \pm 1.17 \\
Residence & & \\
Urban & 46 & 64.8 \\
Rural & 25 & 35.2 \\
Mother education & & \\
Primary & 14 & 19.7 \\
Secondary & 51 & 71.8 \\
high & 6 & 8.5 \\
Mother occupation & & \\
Working & 30 & 42.3 \\
House wives & 41 & 57.7 \\
\hline
\end{tabular}

Figure (1):Clarify that more than half of students not staying in the institution and coming in as school day.

Figure (2): Shows that around two thirds of students need helper to perform certain tasks.

Figure (3): Illustrated that the blinded students had more than three quarters of their knowledge from more than one 
source and the minority having their knowledge from mass media

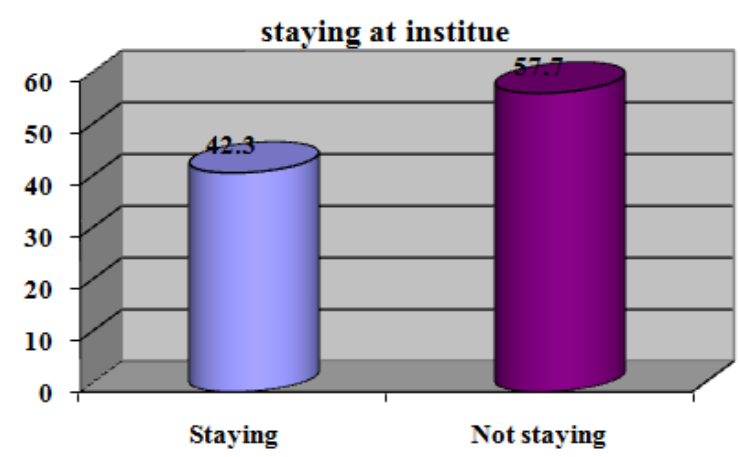

Figure (1). Frequency distribution of study sample regarding staying at institute.

Needs Helper (Career)

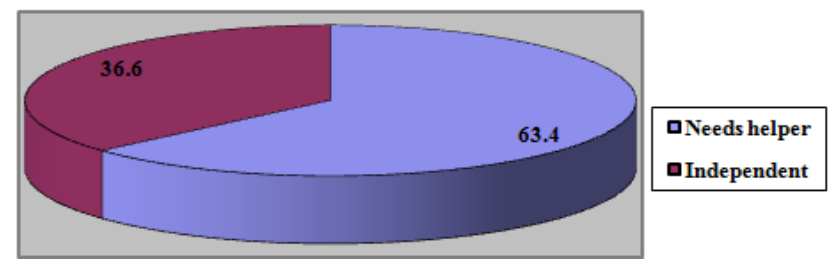

Figure (2). Frequency distribution of study sample regarding needs helper (career).

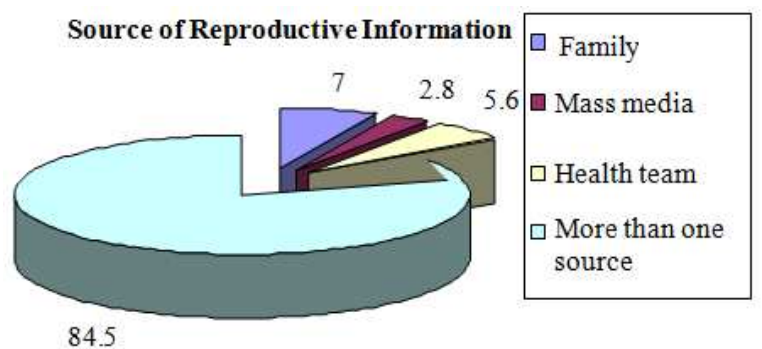

Figure (3). Frequency distribution of study sample regarding sources of students' information.

\subsection{According Research Hypothesis (Table 2-9)}

Table (2): Showed that around one third had dysmenorrhea $(36.6 \%)$ pre program compared by $(33.8 \%)$ post program, with statistically significant differences between health problems pre/post program in last 6months.

Table (3):Showed that there are improvement of students' knowledge regarding reproductive health after implementation the program than before with highly statistically significance differences

Table (4):Shows that a significant improvement between pre/post-test regarding nutrition, personal hygiene, exercise, follow-up, sleep, and reproductive health. Meanwhile there are insignificant statistically relations between pre/posttest in psychological health practices.

Table (5):Describes that the mean and standard division of study sample regarding their reproductive practices in relation to residence. It was showed that a significant improvement between pre-test and post-test regarding nutrition, personal hygiene, exercise, follow-up, sleep, and reproductive health. Meanwhile this improvement insignificant at post-test in psychological.

Table (6): Describes that the mean and standard division of study sample regarding their reproductive practices in relation to presence at institution. It was showed that a significant improvement between pre-test and post-test in and out presence at institution regarding knowledge, nutrition, personal hygiene, exercise, follow-up, sleep, and reproductive health. Meanwhile this improvement insignificant at post-test in psychological.

Table(7):Describes that the mean and standard division of study sample regarding their reproductive practices are a significant improvement between pre-test and post-test in relation to age, regarding knowledge, nutrition, personal hygiene, exercise, follow-up, sleep, and reproductive health. Meanwhile this improvement insignificant at post-test in psychological.

Table (8): Showed that statistically significant relations between total knowledge score and total practices score regarding reproductive health pre and post implementing the program among blinded adolescent students in El-Nor and El-Aml institute.

Table(9): Showed that statistically positive correlation between total knowledge and total practice pre and post implementation the program.

Table (2). Frequency distribution of study sample related to health problems in last 6 months ( $n=71)$.

\begin{tabular}{|c|c|c|c|c|c|c|}
\hline \multirow{2}{*}{ Items } & \multicolumn{2}{|l|}{ Pre } & \multicolumn{2}{|c|}{ Post } & \multirow{2}{*}{$X^{2}$} & \multirow{2}{*}{ p-value } \\
\hline & No & $\%$ & No & $\%$ & & \\
\hline No problems & 8 & 11.3 & 35 & 49.3 & & \\
\hline Pain & 26 & 36.6 & 24 & 33.8 & & \\
\hline Discharge & 0 & 0.0 & 1 & 1.4 & & \\
\hline Heavy menstruation & 3 & 4.2 & 4 & 5.6 & 55.92 & $<0.001$ \\
\hline Irregularity in menstruation & 4 & 5.6 & 3 & 4.2 & & \\
\hline Itching & 2 & 2.8 & 0 & 0.0 & & \\
\hline More than one problem & 28 & 39.4 & 4 & 5.6 & & \\
\hline
\end{tabular}


Table (3). Distribution of students' knowledge regarding reproductive health pre and post program ( $n=71)$.

\begin{tabular}{|c|c|c|c|c|c|c|c|c|}
\hline & \multicolumn{3}{|l|}{ Pre program } & \multicolumn{3}{|l|}{ Post program } & \multirow{3}{*}{$\mathbf{X}^{2}$} & \multirow{3}{*}{ p-value } \\
\hline & $\begin{array}{l}\text { Complete } \\
\text { correct answer }\end{array}$ & $\begin{array}{l}\text { Incomplete } \\
\text { correct answer }\end{array}$ & $\begin{array}{l}\text { Wrong } \\
\text { answer }\end{array}$ & $\begin{array}{l}\text { Complete } \\
\text { correct answer }\end{array}$ & $\begin{array}{l}\text { Incomplete } \\
\text { correct answer }\end{array}$ & $\begin{array}{l}\text { Wrong } \\
\text { answer }\end{array}$ & & \\
\hline & $\%$ & $\%$ & $\%$ & $\%$ & $\%$ & $\%$ & & \\
\hline Meaning & 11.2 & 12.7 & 76.1 & 87.3 & 11.3 & 1.4 & 92.7 & $<0.001$ \\
\hline Parts of reproductive system & 50.7 & 7.0 & 42.3 & 87.3 & 4.2 & 8.5 & 23.3 & $<0.001$ \\
\hline Changes with menstruation & 8.5 & 39.4 & 52.1 & 80.3 & 19.7 & 0.0 & 82.9 & $<0.001$ \\
\hline Dangerous signs & 8.5 & 49.3 & 42.3 & 31.0 & 59.2 & 9.9 & 24.0 & $<0.001$ \\
\hline Normal days of menstruation & 7.0 & 29.6 & 63.4 & 95.8 & 0.0 & 4.2 & 112.1 & $<0.001$ \\
\hline $\begin{array}{l}\text { Function of reproductive } \\
\text { health }\end{array}$ & 9.9 & 40.8 & 49.3 & 74.6 & 16.9 & 8.5 & 62.8 & $<0.001$ \\
\hline Time of ovulation & 14.1 & 40.8 & 45.1 & 66.2 & 33.8 & 0.0 & 56.4 & $<0.001$ \\
\hline $\begin{array}{l}\text { Glands for menstrual } \\
\text { regulation }\end{array}$ & 1.4 & 49.3 & 49.3 & 81.7 & 11.3 & 7.0 & 94.5 & $<0.001$ \\
\hline $\begin{array}{l}\text { Normal periods between } \\
\text { menstruation }\end{array}$ & 2.8 & 29.6 & 67.6 & 66.2 & 19.7 & 14.1 & 67.6 & $<0.001$ \\
\hline Femenial hormones & 28.2 & 45.1 & 26.8 & 2.8 & 97.2 & 0.0 & 47.2 & $<0.001$ \\
\hline Diet increases during puberty & 5.6 & 43.7 & 50.7 & 45.1 & 49.3 & 5.6 & 47.6 & $<0.001$ \\
\hline $\begin{array}{l}\text { Number of changing } \\
\text { menstrual bad }\end{array}$ & 9.9 & 31.0 & 59.2 & 91.5 & 0.0 & 8.5 & 95.7 & $<0.001$ \\
\hline $\begin{array}{l}\text { Practicing sports during } \\
\text { menstruation }\end{array}$ & 19.7 & 40.8 & 39.4 & 78.9 & 15.5 & 5.6 & 51.3 & $<0.001$ \\
\hline
\end{tabular}

Table (4). Differences in reproductive health practices among blinded students pre-post program ( $n=71)$.

\begin{tabular}{lllll}
\hline \multirow{2}{*}{ Total practices mean score } & Pre & Post & t test & P-value \\
\cline { 2 - 4 } & Mean \pm SD & Mean \pm SD & 7.310 & $<0.001$ \\
\hline Nutrition & $11.80 \pm 3.98$ & $15.80 \pm 3.68$ & 8.476 & $<0.001$ \\
Personal hygiene & $8.50 \pm 1.86$ & $11.05 \pm 2.63$ & 11.02 & $<0.001$ \\
Exercise & $4.21 \pm 1.41$ & $6.61 \pm 1.59$ & 14.00 & $<0.001$ \\
Follow-up & $2.07 \pm 1.13$ & $4.38 \pm 1.30$ & 0.434 & $>0.05$ \\
Psychological & $3.52 \pm .98$ & $3.57 \pm 1.06$ & 4.45 & $<0.001$ \\
Sleep & $3.52 \pm 1.11$ & $4.43 \pm 1.50$ & & \\
\hline
\end{tabular}

*Paired t test

Table (5). Differences among the study sample regarding their reproductive health practices in relation to residence ( $n=71)$.

\begin{tabular}{|c|c|c|c|c|c|c|}
\hline \multirow{2}{*}{ Total practices mean score } & \multicolumn{3}{|c|}{ Rural (n= 25) } & \multicolumn{3}{|c|}{ Urban $(n=46)$} \\
\hline & Pre & & Post & Pre & & Post \\
\hline \multirow{2}{*}{ Nutrition } & $10.24 \pm 3.30$ & & $15.28 \pm 4.21$ & $12.65 \pm 4.08$ & & $16.08 \pm 3.37$ \\
\hline & $\mathrm{T}=4.70$ & $\mathrm{P}<0.001$ & & $\mathrm{~T}=4.39$ & $\mathrm{P}<0.001$ & \\
\hline \multirow{2}{*}{ Personal hygiene } & $7.60 \pm 1.22$ & & $11.28 \pm 2.54$ & $9.00 \pm 1.97$ & & $10.93 \pm 2.71$ \\
\hline & $\mathrm{T}=6.52$ & $\mathrm{P}<0.001$ & & $\mathrm{~T}=3.91$ & $\mathrm{P}<0.001$ & \\
\hline \multirow{2}{*}{ Exercise } & $4.64 \pm 1.28$ & & $7.08 \pm 1.73$ & $3.97 \pm 1.43$ & & $6.36 \pm 1.48$ \\
\hline & $\mathrm{T}=5.65$ & $\mathrm{P}<0.001$ & & $\mathrm{~T}=7.85$ & $\mathrm{P}<0.001$ & \\
\hline \multirow{2}{*}{ Follow-up } & $1.76 \pm 1.05$ & & $4.36 \pm 1.25$ & $2.23 \pm 1.15$ & & $4.39 \pm 1.34$ \\
\hline & $\mathrm{T}=7.94$ & $\mathrm{P}<0.001$ & & $\mathrm{~T}=8.23$ & $\mathrm{P}<0.001$ & \\
\hline \multirow{2}{*}{ Psychological } & $3.60 \pm .91$ & & $3.44 \pm 1.29$ & $3.47 \pm 1.02$ & & $3.65 \pm .92$ \\
\hline & $\mathrm{T}=.505$ & $\mathrm{P}>0.05$ & & $\mathrm{~T}=0.85$ & $>0.05$ & \\
\hline \multirow{2}{*}{ Sleep } & $3.48 \pm 1.22$ & & $4.56 \pm 1.52$ & $3.54 \pm 1.06$ & & $4.36 \pm 1.51$ \\
\hline & $\mathrm{T}=2.75$ & $\mathrm{P}=.008$ & & $\mathrm{~T}=3.02$ & $\mathrm{P}=.003$ & \\
\hline
\end{tabular}

*Independent Samples T test 
RasmiaAbd-El Sattar Ali and Ebtisam Mohamed Abd-El Aal: Effect of Health Educational Program for Female Blinded Adolescent Regarding Reproductive Health

Table (6). Differences among the study sample regarding their reproductive health practices in relation to staying at institution ( $n=71$ ).

\begin{tabular}{|c|c|c|c|c|c|c|}
\hline \multirow{2}{*}{ Total practices mean score } & \multicolumn{3}{|c|}{ Staying $(n=30)$} & \multicolumn{3}{|c|}{ Not staying $(n=41)$} \\
\hline & Pre & & Post & Pre & & Post \\
\hline \multirow{2}{*}{ Nutrition } & $10.13 \pm 3.35$ & & $14.9 \pm 4.0$ & $13.02 \pm 3.99$ & & $16.41 \pm 3.31$ \\
\hline & $\mathrm{T}=5.04$ & $P<0.001$ & & $\mathrm{~T}=4.18$ & $\mathbf{P}<0.001$ & \\
\hline \multirow{2}{*}{ Personal hygiene } & $7.56 \pm 1.19$ & & $11.0 \pm 2.5$ & $9.19 \pm 1.97$ & & $11.09 \pm 2.70$ \\
\hline & $\mathrm{T}=6.57$ & $\mathrm{P}<0.001$ & & $\mathrm{~T}=3.64$ & $\mathrm{P}<0.001$ & \\
\hline \multirow{2}{*}{ Exercise } & $4.56 \pm 1.25$ & & $6.96 \pm 1.6$ & $3.95 \pm 1.48$ & & $6.36 \pm 1.49$ \\
\hline & $\mathrm{T}=6.24$ & $\mathrm{P}<0.001$ & & $\mathrm{~T}=7.34$ & $\mathrm{P}<0.001$ & \\
\hline \multirow{2}{*}{ Follow-up } & $1.70 \pm 1.02$ & & $4.26 \pm 1.2$ & $2.34 \pm 1.15$ & & $4.46 \pm 1.34$ \\
\hline & $\mathrm{T}=8.67$ & $\mathrm{P}<0.001$ & & $\mathrm{~T}=7.67$ & $\mathrm{P}<0.00$ & \\
\hline \multirow{2}{*}{ Psychological } & $3.56 \pm 0.89$ & & $3.40 \pm 1.2$ & $3.48 \pm 1.05$ & & $3.70 \pm 0.92$ \\
\hline & $\mathrm{T}=0.60$ & $\mathrm{P}>0.05$ & & $\mathrm{~T}=1.00$ & $\mathrm{P}>0.05$ & \\
\hline \multirow{2}{*}{ Sleep } & $3.60 \pm 1.24$ & & $4.40 \pm 1.5$ & $3.46 \pm 1.02$ & & $4.46 \pm 1.51$ \\
\hline & $\mathrm{T}=2.22$ & $\mathrm{P}<0.05$ & & $\mathrm{~T}=3.49$ & $\mathrm{P}<0.001$ & \\
\hline
\end{tabular}

Independent Samples T test

Table (7). Differences among the study sample regarding their reproductive health practices in relation to age ( $n=71)$.

\begin{tabular}{|c|c|c|c|c|c|}
\hline \multirow{2}{*}{ Total practices main score } & \multicolumn{3}{|c|}{$\leq 15$ year $(n=47)$} & \multicolumn{2}{|l|}{$>15$ year $(n=24)$} \\
\hline & Pre & & Post & Pre & Post \\
\hline \multirow{2}{*}{ Nutrition } & $12.82 \pm 3.8$ & & $15.34 \pm 3.64$ & $9.79 \pm 3.52$ & $16.70 \pm 3.66$ \\
\hline & $\mathrm{T}=3.254$ & $\mathrm{P}<0.05$ & & $\mathrm{P}<0.001$ & \\
\hline \multirow{2}{*}{ Personal hygiene } & $8.91 \pm 1.81$ & & $11.10 \pm 2.63$ & $7.70 \pm 1.73$ & $10.95 \pm 2.71$ \\
\hline & $\mathrm{T}=4.700$ & $\mathrm{P}<0.001$ & & $\mathrm{~T}=4.95 \quad \mathrm{P}<0.001$ & \\
\hline \multirow{2}{*}{ Exercise } & $4.27 \pm 1.40$ & & $6.59 \pm 1.65$ & $4.08 \pm 1.44$ & $6.66 \pm 1.52$ \\
\hline & $\mathrm{T}=7.325$ & $\mathrm{P}<0.001$ & & $\mathrm{~T}=6.03 \quad \mathrm{P}<0.001$ & \\
\hline \multirow{2}{*}{ Follow-up } & $2.23 \pm 1.00$ & & $4.44 \pm 1.28$ & $1.75 \pm 1.32$ & $4.25 \pm 1.35$ \\
\hline & $\mathrm{T}=9.313$ & $\mathrm{P}<0.001$ & & $\mathrm{~T}=6.44 \quad \mathrm{P}<0.001$ & \\
\hline \multirow{2}{*}{ Psychological } & $3.65 \pm .91$ & & $3.68 \pm 1.21$ & $3.25 \pm 1.07$ & $3.37 \pm .64$ \\
\hline & $\mathrm{T}=0.096$ & $\mathrm{P}>0.05$ & & $\mathrm{~T}=0.48 \quad \mathrm{P}>0.05$ & \\
\hline \multirow{2}{*}{ Sleep } & $3.57 \pm 1.09$ & & $4.46 \pm 1.51$ & $3.41 \pm 1.17$ & $4.37 \pm 1.52$ \\
\hline & $\mathrm{T}=3.273$ & $\mathrm{P}<0.05$ & & $\mathrm{~T}=2.43 \quad \mathrm{P}<0.05$ & \\
\hline
\end{tabular}

Independent Samples T test

Table (8). Differences between students' total knowledge and total practices regarding reproductive health $(n=71)$.

\begin{tabular}{llll}
\hline \multirow{2}{*}{ Items } & Pre & Post & T test \\
\cline { 2 - 4 } & Mean \pm SD & Mean \pm SD & \\
\hline Total knowledge score & $10.67 \pm 4.55$ & $14.30 \pm 2.62$ & 9.33 \\
Total practices score & $38.76 \pm 8.95$ & $54.42 \pm 9.48$ & $<0.001$ \\
\hline
\end{tabular}

Paired T test

Table (9). Correlation between total knowledge and total practices pre and post program $(n=71)$

\begin{tabular}{llll}
\hline \multirow{2}{*}{ Items } & \multicolumn{2}{c}{ Total knowledge Pre } & \multicolumn{2}{c}{ Total practices pre } \\
\cline { 2 - 4 } & $\mathbf{r}$ & $\mathbf{P}$ & $\mathbf{r}$ \\
\hline Total knowledge post & .705 & $<0.001$ & - \\
Total practices post & - & - & 0.564 \\
\hline
\end{tabular}

\section{Discussion}

Blindness female adolescent students are obviously disadvantaged as it is hard for them to achieve normal levels of social, emotional and cognitive development. They experience many losses such as self-esteem, physical integrity, mobility, daily living activities, recreation, career, and personal independence as well as social adequacy ${ }^{[9]}$.

According to students' demographic characteristics; the current study showed that that the mean age of students $15.07 \pm 1.17$, more than half not staying at El-Nor and El Amal institute about two thirds living in urban area; regarding mother education the minority were completed university education, while more than half of them were housewives. These results in line with $\mathrm{Killer}^{[10]}$, who revealed that highest prevalence of parents of female blindness were found among low educational and only fifth of them completed their university education due to low 
socio-economic standards of their families. While Montgomery and Morris ${ }^{[1]}$, reported that the majority of student's mothers were housewives and nearly half of them of students' mothers were illiterate in relation to needs for career the current study revealed that around two thirds of students needs helper (career) to perform certain tasks (Figure 2): this result in agreement with Allen and Mor ${ }^{[12]}$, who reported that the prevalence of unmet needs for assistance of blindness with daily living activities. Another study conducted by Hayaslin ${ }^{[13]}$, revealed that eighty three of female adolescent students with blind live in nursing homes because they are unable to take care of themselves and they did not have any assistance in their families to provide them with essential care.

According to source of students' information the current study revealed that more than three quarters of their knowledge gaining from more than one source and the minority from mass media (figure 3 ). This incongruent with Wahba and Fahimi ${ }^{[1]}$, who reported that media have a profound impact on young people's knowledge, beliefs, and attitudes related to reproductive health. And three out of five female respondents considered their mothers as their main source of information about puberty. This may be explained that female blinded adolescents students, had closed social relation only with friends in institute, their families, teachers, and media.

Regarding students' practices toward reproductive health the current study revealed that a significant improvement between pre-test and post-test regarding nutrition, personal hygiene, exercise, follow-up, sleep, and reproductive health. Meanwhile this improvement insignificant at post-test in psychological status,table(2). This results in accordance with Dlunmk $^{[14]}$, who stated that more than three quarters of blind female adolescent students had normal sleeping pattern, while less than quarter of them had sleeping problems such as interrupted sleep, difficulty to sleep or both of them, and insomnia. This explained by may be the ability of some disabled female adolescent students to adapt and accept their physical limitation and find a variety of compensatory motor, and intellectual pursuits to achieve certain activities of daily living.

Regarding nutrition the currentstudy results agreement with Kopke ${ }^{[15]}$, who reported that, blind female adolescent students require more energy for growth and increased in takes of many specific nutrients to support the body's physiological development although adolescent are in a great need of good nutrition. Their diet doesn't often reflect their requirements they themselves seem to believe that busy lifestyle coupled with difficulty of obtaining nutritious food leads to unhealthy eating.

Abo-Elazm, ${ }^{[16]}$, who study was carried on adolescents, school girls who revealed that about one third of the sample had poor nutritional habits and didn't consume sufficient amount of their nutritional need

As regard Physical activities and sport Patrick and Salis ${ }^{[17]}$, they stated that are playing an important role in enhancing blind female adolescent students' self-esteem and confidence and stress reduction, decreased risk of many diseases and premature deaths. Life-style pattern is important as it helps in identifying many health related behaviors developed during adolescence.

The present study portrayed that blindness affect over-all impression for blind female adolescent students', Table (3):Describes that the mean and standard division of study sample regarding their reproductive practices in relation to residence which showed that a significant improvement between practices mean scores pre-test and post-test regarding nutrition, personal hygiene, exercise, follow-up, sleep, and reproductive health. Meanwhile these improvements insignificant at practices mean scores post-test in psychological status. This in line with Koura [18], who stated that blind female adolescent students with the same age, it is observed that being disabled created other specific needs for those with blindness related to health, educational requirement, developing human attachment, motor development, play socialization, achieving independence in daily living activities, development of positive self-concept, cognitive and learning.

According to the sleeping pattern of blinded students the study showed that their sleeping pattern was improved after implementing the program this agreement with Dlunmk ${ }^{[14]}$, who founded that More than three quarters of blind female adolescent students had normal sleeping pattern, while less than quarter of them had sleeping problems such as interrupted sleep, difficulty to sleep or both of them, and insomnia.

According to the students' knowledge the current study revealed that statistically significant relations between total knowledge score regarding reproductive health pre and post implanting the program among blinded adolescent students in El-Nor and El-Aml institute. This may be due to the trials of blind female adolescent students to divert their attention from their disabilities and gain their attention related to education, physical health and increasing their self-esteem. These results in accordance with Wahba and Fahimi ${ }^{[1]}$, they reported thatIn Egypt, young people receive very limited reproductive health education through the formal school system. Both national and subnational surveys have shown that young Egyptians lack basic information on reproductive health topics and often receive information from sources that may be misleading or inaccurate. Surveys also have shown that both young people and their parents would like more information on these topics to be taught at school.

\section{Conclusions}

Adolescents blinded students in El-Nor and El-Aml institute their knowledge was upgrading after implementation of the health education program and their practices were improved especially for nutrition and personal hygiene.

\section{Recommendations}

- Continuous health educational program should be 
provided to adolescents blinded students about nutrition, and personal hygiene.

- Further researches regarding this target group from different aspects.

\section{References}

[1] Wahba M., and Fahimi F. (2012):The Need for Reproductive Health Education in Schools in Egypt, available at: www.prb.org

[2] McConachieH., and Moore V. (2011): Early Expression Language of severely visually impaired children, Developmental Medicine and Child Neurology $7^{\text {th }}$ ed. Pp 230240.

[3] Christie D. and Viner R. (2012): Adolescent development. Available doi: 10.1136/bmj. 3307486.301 pmc 548185. PMID 15695279; Pp 301-304

[4] WHO (2012): Global Prevalence of Vitamin A Deficiency. Geneva. Pp 8-12.

[5] Obsorn M., Dewill T., First L., and Zenel J. (2012): Pediatrics. 3rd ed. USA: Elsevier Mosby Company. Pp 20-51.

[6] Wong's L., Hockenberry M., and Wilson D. (2012): Nursing Care of Children and Asolescent $8^{\text {th }}$ ed. Boston: Mosby Co. Pp1097-1099.

[7] Ramadan R. (2011): Epidemiology of Blindness and Visual Impairment in adult of Ismailia Government. Zagazig University, Faculty of Medicine. Ophthalmology department. Egypt. Pp 95-99.

[8] Pokharel G. (2010): Prevalence of blindness and cataract surgery. British Journal of Ophthalmology. Pp 600-626.
[9] Dworkin P. (2011): Pediatrics 6th ed. London., Williams and Wikins Company. Pp 291.

[10] Killer A. (2009): Public Health in New York City. Confronting Epidemics of the modern era international Journal of Epidemiology. Pp 112-127.

[11] Montgomery B., and Morris L. (2011): Surviving: Coping with life crisis., $5^{\text {th }}$ ed . London., Lippincott Williams and Wikins Company. Pp 80- 85.

[12] Allen S., and Mor V.(2011): the prevalence and consequences of unmet need contrasts between older and younger adults with disability. Med care. Pp 1132-1134.

[13] Hayaslin M. (2012): A study of social needs and human relations of residents of a nursing home for the physically handicapped. Journal of Nippon koshu Eisei Zaashi. Pp 825835 .

[14] Dlunmk C. (2010): Adolescent Health: priorities for the next millenniym Maternal Adolescence Jornal.

[15] Kopke A. (2011): Nutritional Dirty Habits of Adolescent in Oman. Ecology of food nutrition. Pp 227-237.

[16] Abo El-Azm G. (2011): Weight Modification Efforts reported by black and white preadolescent girls' National Heart lung blood institute growth and health study. Pediatrics Journal. pp 63-65.

[17] Patrick K., and Salis J. (2010): Physical Activity Guidance for Adolescents Pediatrics Exercise Science. Pp 302-314.

[18] Koura R. (2012): Occurrence of Eye Disorders among Adult in Rural Area. Bulltetin of High Institute of public Health Alex. Egypt. Pp 832. 